\title{
Ecological association between COVID-19 deaths and vitamin D deficiency among older adults: An international country-level systematic review and analysis
}

\author{
Kaylin Beiter ( $\sim$ kbeite@lsushc.edu ) \\ Louisiana State University Health Sciences Center School of Public Health https://orcid.org/0000-0001-8691-0694 \\ Frank H Lau \\ Louisiana State University Health Sciences Center School of Medicine \\ Denise Danos \\ Louisiana State University Health Sciences Center School of Public Health
}

\section{Research article}

Keywords: COVID-19, vitamin D deficiency, vitamin D insufficiency

Posted Date: October 1st, 2020

DOl: https://doi.org/10.21203/rs.3.rs-80017/v1

License: @ (7) This work is licensed under a Creative Commons Attribution 4.0 International License. Read Full License 


\section{Abstract \\ Background}

The COVID-19 pandemic has been consistently associated with disproportionately high mortality among older adults, regardless of nation of origin. Previous research on pneumotropic viruses demonstrated an association between host vitamin $\mathrm{D}$ levels and viral disease state. Vitamin D deficiency (VDD) also disproportionately impact older adults. The objective of this study was to evaluate VDD and COVID-19 mortality worldwide during the first 50 days of the pandemic as experienced by each country.

\section{Methods}

Country-specific VDD prevalence among older adults was evaluated according to a systematic literature search of PubMed, CINAHL, EMBASE, and SCOPUS during April 2020. Data were obtained from the public Our World in Data database which reports COVID-19 mortality from European Centre for Disease Prevention and Control and country population characteristics, size and proportion of the population greater than 65 years, from the United Nations Department of Economic and Social Affairs. Country-specific cumulative mortality was modeled via negative binomial random coefficient growth curve models.

\section{Results}

Among 29 countries included in this analysis, VDD prevalence among older adults ranged from $6.9 \%$ in Canada to $69 \%$ in France. Cumulative COVID-19 deaths up to day 50 within each country, modeled via exponential growth curves, demonstrated an association with country-level VDD $(p=0.0538)$. However, the association was not robust when controlling for proportion of older adults in each country $(p=0.2135)$.

\section{Conclusions}

This ecological analysis is further evidence for VDD correction as a component of COVID-19 treatment, especially among older individuals. Inclusion of data cross-culturally (i.e., collected from countries worldwide) supports the theory that VDD is a universal mechanism contributing to COVID-19 mortality. Though definitive randomized controlled trials are still needed, the current study provides support for VDD screening and correction as the influenza season rapidly approaches in the Northern hemisphere.

\section{Background}

Sars-CoV-2 mortality differs widely by country. Factors contributing to this variation include differences in testing/reporting, access to healthcare resources, and the presence of and public adherence to policy interventions such as social distancing and mask-wearing. However, underlying biological mechanisms may also impact viral mortality. It is important to evaluate biological reasons for the difference in COVID-19 mortality, as failure to do so limits worldwide capacity to develop pharmacologic responses for treatment of infected symptomatic individuals. Furthermore, biological mechanisms affecting viral mortality are critical to providing insight as to why some infected individuals remain asymptomatic while others develop COVID-19. This latter phenomenon was recently observed in a population of individuals experiencing homelessness in Boston, Massachusetts: a stunning $88 \%$ of individuals testing positive for Sars-CoV-2 were asymptomatic. ${ }^{1}$ This is double the otherwise-reported asymptomatic rate of $40-45 \%{ }^{2}$

One potential biological reason for differences in mortality is vitamin D status. Low vitamin $D$ is known to increase risk of both upper and lower respiratory tract infections. ${ }^{3}$ A recent (2019) systematic review and meta-analysis clarified that among individuals with vitamin D insufficiency (VDI) in particular, respiratory infection risk is negatively associated with vitamin D levels. ${ }^{4}$ Thus, vitamin $D$ status is likely relevant for the contemporary pneumotropic Sars-Cov-2 virus.

\section{Vitamin D and the Immune System}

Several molecular mechanisms for this relationship between VDI and viral infection have been proposed. Vitamin D normally suppresses Th1 cell proliferation and enhances a shift towards Th2 cellular responses; consequent reductions in interferon-gamma 
and interleukin (IL)-2 follow. ${ }^{5}$ Similarly, vitamin D modulates dendritic cell signaling to reduce IL-12 production (which limits development of a Th1 response) and promotes IL-10 (thus inducing a tolerogenic, non-inflammatory response). ${ }^{6}$ Therefore, Th1 cells are increased in vitamin D insufficiency or deficiency (VDI/VDD). This overall shift towards a pro-inflammatory Th1-dominated state characterizes the immune status of symptomatic COVID-19 patients. ${ }^{7}$ In addition, vitamin D interferes with enveloped viruses via a cathelicidin-mediated disruption of the viral envelope. ${ }^{5}$ Cathelicidin is an endogenous anti-microbial peptide; it is upregulated in lung epithelial cells in the presence of vitamin D. ${ }^{8}$ Cathelicidin-mediated disruption has also been demonstrated for other viral and bacterial pathogens. ${ }^{5,8}$ Therefore again, low vitamin D status is associated with a reduction in capacity to respond to viral infection.

Supplementation of vitamin $\mathrm{D}$ during influenza virus infection has been shown to reduce excessive pro-inflammatory cytokine production, thus limiting inflammation-induced complications (e.g., pulmonary edema). ${ }^{6}$ Some respiratory viruses, such as respiratory syncytial virus and rhinovirus, downregulate vitamin D receptor levels in human bronchial epithelial cells. ${ }^{9}$ Exogenous supplementation improved in vitro antiviral activity through the aforementioned vitamin D-mediated cathelicidin pathway.

Vitamin D also suppresses CD26, a presumed adhesion molecule for Sars-Cov-2 virus host cell entry. ${ }^{10}$ Given these links between vitamin D status and COVID-19, calls for vitamin D supplementation among vulnerable groups have been made: older adults, nursing home residents, individuals with diabetes mellitus or obesity, individuals with darker skin, health care workers, and individuals who smoke. ${ }^{10}$

\section{Epidemiology of VDI and VDD}

The Endocrine Society defines VDI and VDD as serum 25(OH)D levels below $75 \mathrm{nmol} / \mathrm{L}(30 \mathrm{ng} / \mathrm{mL})$ or $50 \mathrm{nmol} / \mathrm{L}(20 \mathrm{ng} / \mathrm{mL})^{11}$. VDI is one of the most common nutritional deficiencies worldwide. ${ }^{12}$ Traditionally, VDI and VDD risk is highest among pregnant women, children, older individuals, institutionalized populations, and non-Western Immigrants. ${ }^{13} \mathrm{~A}$ study of healthy French adults demonstrated $80.3 \%$ with vitamin D levels $<30 \mathrm{ng} / \mathrm{mL}$ and $34.6 \%$ with vitamin D levels below $20 \mathrm{ng} / \mathrm{mL} .{ }^{14}$ In this same study, VDI of $<20 \mathrm{ng} / \mathrm{mL}$ was associated with older age, living at a higher latitude, BMI $>24 \mathrm{~kg} / \mathrm{m}^{2}$, or having been sampled between the winter months of January and March. ${ }^{14}$ Globally, winter months consistently demonstrate increased VDI. ${ }^{13,15}$ The positive association between latitude and vitamin $D$ status is stronger among Caucasians than non-Caucasians. ${ }^{16}$ However, among a geographicallyrepresentative study of healthy Chinese adults, younger adults (18-39 years) had lower vitamin D levels than older adults (> 49 years), possibly due to increased time spent indoors by working, young adults. ${ }^{17}$ No significant geographic differences were noted according to distance from the equator (and hence sunlight exposure), which the authors ascribed to the study's inclusion of coastal cities where fish consumption is high. ${ }^{17}$ Finally, low vitamin $D$ status can occur for a variety of factors even at low-latitude countries; a study of healthy adults in Syria found a positive association between VDI and female gender, and VDI and hijab-wearing; seasonality of VDI was noted in men, but not women for this study as well. ${ }^{18}$

Within the United States, the National Health and Nutrition Examination Survey has demonstrated increased risk for VDI among the following: African-American individuals, individuals with obesity, and individuals who self-rate as generally having poor health. Over

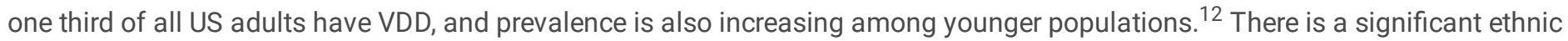
difference in VDI, with higher prevalence noted among non-Hispanic blacks as compared to non-Hispanic whites. ${ }^{13}$ This difference according to skin pigmentation is largely due to differences in dermal metabolism of relevant vitamin D precursors. Older adults often similarly demonstrate lower levels of vitamin D due to reduced dermal metabolism. ${ }^{13}$ In addition, VDI also parallels US socioeconomic disparities; socioeconomic achievement, measured by completion of a college degree, is significantly negatively associated with VDI. ${ }^{19}$ Among respondents with available vitamin D level data, $82 \%$ of African-Americans had VDI, followed by $69.2 \%$ of Hispanics. ${ }^{20}$

\section{Study Purpose}

The factors associated with low vitamin D status are similar to those risk factors associated with COVID-19. ${ }^{21}$ Given the global importance of understanding the biological mechanisms underlying morbidity and mortality of Sars-CoV-2, the goal of this study is to evaluate the country-level relationship between COVID-19 mortality and VDD. Because vitamin D levels and clinical outcomes have been shown to be more pronounced among patients with lower vitamin D status, ${ }^{4}$ VDD was specifically selected as the condition of analysis for this study. 
Early investigations of this relationship have reported associations between population level vitamin D levels and COVID-19 impact in terms of population case rate, case mortality rate and population mortality rate ${ }^{22-25}$. However, these studies have relatively small sample sizes, focus on homogenous European populations, and are cross-sectional in nature, and thus do not provide insight to the impacts over time as the epidemic unfolded. Additionally, these studies did not justify the use of Pearson correlation or regression to assess the relationship, which assumes distribution of rates are normally distributed. To better understand the potential association between COVID-19 mortality and vitamin D deficiency in international populations, this study will assess determinants of COVID-19 deaths during the initial outbreak period in each country. We have focused on the number of deaths as it is clinically significant representation of disease severity and impact and it does not depend on testing strategies in each country.

Cumulative infectious disease death curves are typically visualized on a logarithmic-scale as early infectious disease growth is exponential. Over time, the exponential growth slows due to disease management and control (i.e. "flatten the curve") and reduced population susceptibility (i.e. herd immunity, risk factors), resulting in an "S" shaped curve. Figure 1 shows the COVID-19 death curve for France from March 6 through July 20, 2020. An exponential growth model for the first 30 days indicated deaths were doubling approximately every 3 days, then the rate of increase began to slow. Many factors influence the shape and scale of the cumulative death curve for a country, including population size, the prevalence of risk factors like age and health status, and disease control measures.

COVID-19 has disproportionately impacted older individuals. In the US, it is estimated that $80 \%$ of the deaths are in people 65 years or older $^{26}$. In addition to age-related changes in vitamin D metabolism, modifiable determinants of deficiency within older adult or elderly populations include medication polypharmacy, inadequate nutrition, and lifestyle changes lowering natural sun exposure. ${ }^{27-30}$ Therefore, we have conducted an ecological country-level study of the relationship between the rate of vitamin $D$ deficiency among older adults and cumulative COVID-19 deaths in countries during the initial outbreak period.

\section{Methods}

Data for this study was extracted from the "Our World in Data" data portal of the Oxford Martin Programme on Global Development at the University of Oxford on July $20,2020^{31}$. In addition, published literature were searched systematically to determine populationlevel vitamin D status.

Mortality and Population Data

The Our World in Data public COVID-19 dataset contains number of cases and deaths reported by the European Centre for Disease Prevention and Control by country by day since the inception of the pandemic in December 2019. The dataset also contains current estimates of population size and proportion of the population 65 and older from by the United Nations, Department of Economic and Social Affairs, Population Division.

Vitamin D Data

Databases searched include PubMed, CINAHL, EMBASE and SCOPUS in April 2020. Search terms included "vitamin D," and "insufficiency OR deficiency OR status." Separate searches were performed by region by the addition of region name in the search ("Africa”, "Asia", "Australia”, "Europe”, "North America”, "South America”). Studies published from January 2010 to April 2020 were included. This search yielded a total of 7,820 unique records. Records were then evaluated for relevance to the research question by two separate reviewers. The initial search also excluded case reports, reviews and meta-analyses, and case-control studies. Clinical trials were included only if the control group was population based. A total of 6,357 records were excluded based on these criteria.

After initial review, 7,820 unique records were evaluated for relevance to the research question. A total of 110 studies contained data pertaining to the research question of population-level data of VDD among older adults. These studies were ranked by country based on the study population, (1) country-wide population based, (2) regional population-based, (3) study specific. The most representative study with the most recent data of data collection was used for each country (See Table 1). Data were collected on the time and location of data collection, study population, laboratory methods, sample size and results. Studies were excluded if they did not collect data on elderly individuals of both sexes, or if they did not present information on vitamin D deficiency. We selected the Endocrine Society's definition of vitamin D deficiency as less than $50 \mathrm{nmol} / \mathrm{L}(20 \mathrm{ng} / \mathrm{ml})$. 
Table 1

Literature on vitamin D deficiency among older adults

\begin{tabular}{|c|c|c|c|c|c|c|c|c|}
\hline ID & Country & $\begin{array}{l}\text { vitamin D } \\
\text { Deficiency }\end{array}$ & $\begin{array}{l}\text { Year of } \\
\text { Data } \\
\text { Collection }\end{array}$ & $\begin{array}{l}\text { Season of } \\
\text { Collection }\end{array}$ & $\begin{array}{l}\text { *Age of } \\
\text { Participants }\end{array}$ & $\begin{array}{l}\text { Total } \\
\text { N }\end{array}$ & $\begin{array}{l}\text { Participant } \\
\text { Sex } \\
\text { Ratio } \\
\text { (Female/Male) }\end{array}$ & $\begin{array}{l}\text { Method of } \\
\text { vitamin D } \\
\text { Quantification }\end{array}$ \\
\hline AUS & Australia 41 & $36.0 \%$ & $2009-2010$ & Spring & $60-85$ & 72 & 2.27 & CLIA \\
\hline BEL & Belgium ${ }^{42}$ & $65.7 \%$ & $2008-2009$ & Whole Year & $80+$ & 367 & 1.76 & CLIA \\
\hline BRA & Brazil $^{43}$ & $58.0 \%$ & $2002-2007$ & Whole Year & $72.8 \pm 4.8$ & 908 & 1.46 & RIA \\
\hline CAN & Canada $^{44}$ & $6.9 \%$ & $2012-2013$ & Whole Year & $50-80$ & 2,119 & 1.84 & CLIA/LCMS \\
\hline CHE & Switzerland ${ }^{45}$ & $34.4 \%$ & $2009-2010$ & Whole Year & $60+$ & 1,470 & 1.15 & - \\
\hline $\mathrm{CHN}$ & China ${ }^{46}$ & $39.1 \%$ & $2010-2013$ & Whole Year & $60+$ & 6,014 & 1.04 & RIA \\
\hline DEU & Germany $^{47}$ & $49.4 \%$ & $2009-2010$ & Whole Year & $65+$ & 1,385 & 0.75 & CLIA/LCMS \\
\hline ECU & Ecuador $^{48}$ & $21.6 \%$ & 2009 & Summer & $71.0 \pm 8.3$ & 2,374 & 1.21 & HPLC \\
\hline EGY & Egypt $^{49}$ & $12.0 \%$ & - & - & $60+$ & 176 & - & - \\
\hline EST & Estonia $^{50}$ & $55.0 \%$ & $2001-2002$ & Whole Year & $74 \pm 6$ & 900 & 1.99 & LCMS \\
\hline FIN & Finland ${ }^{51}$ & $65.1 \%$ & 1998-2001 & Whole Year & $53-73$ & 1,421 & 0.97 & LCMS \\
\hline FRA & France ${ }^{50}$ & $69.0 \%$ & $2001-2002$ & Whole Year & $73 \pm 6$ & 695 & 1.45 & LCMS \\
\hline GBR & $\begin{array}{l}\text { United } \\
\text { Kingdom } 52\end{array}$ & $55.3 \%$ & $2012-2013$ & Whole Year & $66.4 \pm 8.8$ & 6,004 & 1.21 & CLIA \\
\hline GRC & Greece $e^{50}$ & $59.0 \%$ & $2001-2002$ & Whole Year & $71 \pm 4$ & 578 & 1.15 & LCMS \\
\hline IND & India 53 & $56.3 \%$ & $2014-2015$ & Whole Year & $60+$ & 298 & 0.54 & RIA \\
\hline IRL & Ireland 54 & $42.5 \%$ & $2009-2011$ & Whole Year & $50-80$ & 5,356 & 1.14 & LCMS \\
\hline ITA & Italy 55 & $64.2 \%$ & $1998-2000$ & Whole Year & $65+$ & 867 & 1.30 & RIA \\
\hline JPN & Japan $^{56}$ & $53.6 \%$ & $2011-2013$ & Whole Year & $40-74$ & 9,084 & 1.26 & CLIA \\
\hline KOR & $\begin{array}{l}\text { South } \\
\text { Korea }^{57}\end{array}$ & $59.7 \%$ & $2010-2014$ & Whole Year & $65+$ & 3,757 & 1.26 & RIA \\
\hline MEX & Mexico 58 & $53.2 \%$ & 2012 & Whole Year & $63.4 \pm 9.5$ & 1,772 & 1.42 & CLIA \\
\hline NLD & Netherlands ${ }^{59}$ & $26.4 \%$ & $2008-2009$ & Whole Year & $60-98$ & 915 & 1.09 & RIA \\
\hline NOR & Norway ${ }^{50}$ & $27.0 \%$ & $2001-2002$ & Whole Year & $73 \pm 6$ & 636 & 1.17 & LCMS \\
\hline PRT & Portugal ${ }^{60}$ & $29.4 \%$ & $2015-2016$ & Winter/Spring & $>65$ & 1,500 & 1.39 & CLIA \\
\hline ROU & Romania ${ }^{61}$ & $28.3 \%$ & $2012-2014$ & Whole Year & $61-70$ & 1,030 & 6.92 & HPLC \\
\hline RUS & Russia ${ }^{62}$ & $50.0 \%$ & - & - & $65+$ & 506 & - & CLIA \\
\hline \multicolumn{9}{|c|}{$\begin{array}{l}\text { RIA: Radioimmunoassay; CLIA: Chemiluminescent immunoassay; LCMS: Liquid chromatography tandem mass spectrometry; } \\
\text { HPLC: High performance liquid chromatography }\end{array}$} \\
\hline $\begin{array}{l}\text { Jat } \\
\text { evia }\end{array}$ & $\begin{array}{l}\text { reported acc } \\
\text { or range. }\end{array}$ & ig to their & sentation by & ch individual & y. Age was $r$ & rted & ange, mean $\pm \mathrm{s}$ & ard \\
\hline
\end{tabular}




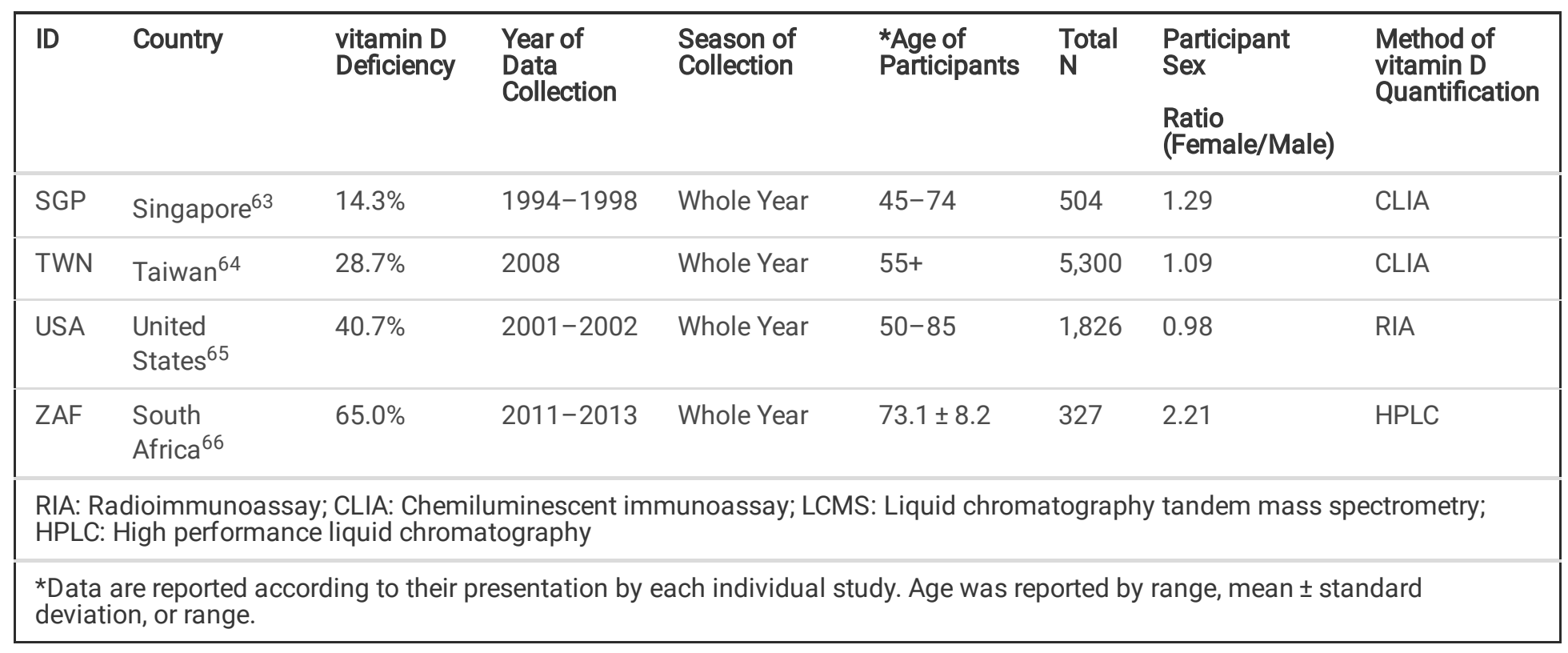

\section{Statistical Analysis}

The primary outcome was cumulative COVID-19 deaths, starting from the day of at least 5 total confirmed deaths in a country. Cumulative death curves exhibit early exponential growth followed by slower or variable growth rates until the outbreak is saturated, which would be evident by a stable, non-increasing trend segment. Cumulative deaths were modeled via random coefficient negative binomial growth curve models. Our hypothesis was that the country VDD prevalence among older adults was associated with COVID19 deaths in a country during the early period of outbreak. The initial model included linear and quadratic effects of time, VDD prevalence, and two way interactions between VDD prevalence and time terms as fixed effects. The model intercept and time terms were included as random effects to account for variability among countries. Additional models included country population size and the proportion of the population that is 65 and older as covariates. All covariates were centered at the mean.

\section{Results}

Table 1 contains details of the international vitamin D literature review and corresponding vitamin D deficiency rates among older adults for the 29 countries in the study. Rates of vitamin D deficiency ranged from $6.9 \%$ in Canada to $69 \%$ in France. A lack of fit test to evaluate residual time trends in the initial VDD model indicated that cumulative deaths up to day 50 were fit well by the model with linear and quadratic time effects ${ }^{32}$. Thus, the study period was 50 days, beginning on the first day when the country reached 5 confirmed COVID-19 deaths (see Fig. 2).

Results from the random coefficient growth curve models are provided as Table 2. The initial test of our hypothesis (Model 1), indicated a marginally significant association between vitamin $D$ deficiency and early exponential growth of COVID-19 deaths in a country $(p=0.0538)$. Adjusting for population size the relationship remained marginally statistically significant $(p=0.0512)$. However, the relationship between VDD in older adults and COVID-19 deaths was not statistically significant after controlling for the proportion of older adults in the population $(p=0.2135)$. 
Table 2

Parameter estimates from negative binomial random coefficient growth curve models of COVID-19 deaths.

\begin{tabular}{|c|c|c|c|c|c|c|c|c|c|}
\hline & \multicolumn{3}{|l|}{ Model 1} & \multicolumn{3}{|l|}{ Model 2} & \multicolumn{3}{|l|}{ Model 3} \\
\hline & Estimate & Standard & $\mathrm{p}$-value & Estimate & Standard & $\mathrm{p}$-value & Estimate & Standard & $\mathrm{p}$-value \\
\hline & & Error & & & Error & & & Error & \\
\hline Intercept & 1.9466 & 0.1059 & $<.0001$ & 1.9382 & 0.1013 & $<.0001$ & 2.0429 & 0.1171 & $<.0001$ \\
\hline Time & 0.1993 & 0.0171 & $<.0001$ & 0.1963 & 0.0171 & $<.0001$ & 0.2095 & 0.0155 & $<.0001$ \\
\hline Time*Time & -0.0020 & 0.0002 & $<.0001$ & -0.0020 & 0.0002 & $<.0001$ & -0.0022 & 0.0000 & $<.0001$ \\
\hline VDD & -0.3021 & 0.5634 & 0.5962 & -0.3423 & 0.5375 & 0.5298 & -0.3404 & 0.6704 & 0.6162 \\
\hline Time*VDD & 0.1806 & 0.0936 & 0.0538 & 0.1826 & 0.0936 & 0.0512 & 0.1122 & 0.0901 & 0.2135 \\
\hline Time*Time*VDD & -0.0019 & 0.0011 & 0.0811 & -0.0019 & 0.0011 & 0.0771 & -0.0010 & 0.0010 & 0.3354 \\
\hline Population & & & & 0.0297 & 0.0264 & 0.2712 & -0.0090 & 0.0356 & 0.8036 \\
\hline Time*Population & & & & 0.0028 & 0.0047 & 0.5501 & 0.0065 & 0.0048 & 0.1763 \\
\hline Time*Time*Population & & & & 0.0000 & 0.0001 & 0.6319 & -0.0001 & 0.0000 & $<.0001$ \\
\hline Elderly & & & & & & & -1.1395 & 2.1938 & 0.6082 \\
\hline Time*Elderly & & & & & & & 0.5717 & 0.2964 & 0.0540 \\
\hline Time*Time*Elderly & & & & & & & -0.0086 & 0.0033 & 0.0102 \\
\hline \multicolumn{10}{|c|}{ VDD = vitamin D Deficiency; Time was measured in days starting from the day of the 5th confirmed COVID-19 death in a country. } \\
\hline Intercept and time terms & ind & in the mod & rond & effects. A & covariates & not & d on the s & nple mean. & \\
\hline
\end{tabular}

\section{Discussion}

In an international country-level analysis of vitamin D deficiency in older individuals and COVID-19 deaths, we found a marginally significant association. The association remained when adjusting for the size of the population, but was not robust to adjusting for the age structure. This suggests the association between older adult population vitamin D levels and mortality is partially confounded by the proportion of population 65 years and older. At the population level, a greater relative proportion of older adults in a country may be associated with societal factors that affect vitamin D deficiency in this population such as differences related to housing/institutionalization, nutrition, physical activity, and/or healthcare services, which would indicate a mediating role of vitamin D deficiency. Alternatively, unobserved factors may account for the observed relationships between age structure, vitamin $D$ deficiency and COVID-19 mortality.

Early cross-sectional ecological analyses have also reported evidence of an association between vitamin D deficiency and COVID-19 in Europe ${ }^{22-25}$. A marginal association between mean vitamin D levels and COVID-19 case and mortality rate $(p=0.05)$ was initially reported in a study of 20 European countries in April $2020^{22}$. Another study assessed the association between mean $250 \mathrm{HD}$ in elderly residents to case mortality rate (CMR) in April 2020 , in a limited sample of countries ${ }^{24}$. When restricting the sample to countries with similar testing strategies, this study reported a linear relationship between mean vitamin D levels and CMR $(p=0.014)$, and concluded that mean vitamin $D$ was a better predictor for CMR than age-distribution, and comorbidities (diabetes and heart disease) although the sample size was extremely small $(n=6)$. Another ecological analysis of COVID-19 population mortality rates in June 2020 reported a strong linear correlation $(p=0.01)$ between mortality and severe vitamin $D$ deficiency $(25 \mathrm{nmol} / \mathrm{L})$ in the general population of 10 European countries ${ }^{25}$. However, this association was not significant when using rates of vitamin $D$ deficiency with a cutoff of $50 \mathrm{nmol} / \mathrm{L}$. While our analysis does have a larger international sample of countries $(n=29)$ it does suffer from similar limitations of other ecological studies. 
There is also evidence of a link between vitamin D deficiency and COVID-19 infection and severity from individual level analyses ${ }^{33-35}$. Single center studies in Switzerland and the US reported significantly lower serum vitamin D levels in individuals that tested positive for Sars-CoV- $2^{34,35}$. A meta-analysis of 7 international studies concluded that serum vitamin D was significantly lower in COVID-19 patients with poor prognosis ${ }^{33}$. Ultimately, ecological and cross-sectional study designs are not fully able to control for possible confounding by factors associated with vitamin $\mathrm{D}$, and a potential causal relationship would need to be confirmed in randomized clinical trials.

Clinical trials are underway world-wide to comprehensively assess the efficacy of vitamin D supplementation among individuals with COVID-19 and as a prophylactic measure among non-infected, high-risk individuals. ${ }^{36}$ Results of these trials are highly anticipated. In the meantime, the relationship between vitamin D supplementation and VDI/VDD correction has been evaluated via randomized controlled clinical trials with other upper respiratory viral pathogen outcomes. A 2017 Cochrane review found that vitamin D supplementation was an effective prophylactic measure against viral respiratory infections with the greatest benefit experienced by individuals with initial low vitamin D levels. ${ }^{37}$

Vitamin D supplementation has also been studied in conjunction with influenza vaccine efficacy among people with VDI. Though vitamin $D$ supplementation was associated with a tolerogenic immune response characterized by increased TGF-beta and a lower Th1:Th2 cell ratio, relative to the vaccine-only group, supplementation was not associated with differences in either antibody titers nor cathelicidin levels. ${ }^{38}$ Thus, while vitamin D supplementation may indeed be one mechanism to ameliorate observed differences in COVID-19 disease severity, it is possible that VDI/VDD correction may not reduce viral mortality. In COVID-19, VDI has also been associated with a higher level of necessary care among hospitalized patients: prevalence of VDI was identified among $85 \%$ of ICUadmitted patients as compared to $57 \%$ of floor patients ${ }^{39}$. VDD has been associated with increased odds of testing positive for COVID-19 among patients at a University of Chicago hospital ${ }^{34}$.

In any case, the known relationship between VDD and influenza infection severity and the relative safety of vitamin D supplementation has resulted in calls for increased supplementation, identification, and correction of VDI/VDD as the winter season approaches in the Northern hemisphere and as coincident infections with Sars-Cov-2 and influenza viruses is expected ${ }^{40}$.

\section{Limitations}

There are a number of limitations to of the present study. Firstly, while the marginal ecological association between the rate of vitamin D deficiency among older adults and COVID-19 deaths at the population level suggests vitamin D deficiency is an important COVID-19 risk factor, this study does not imply the relationship exists at the individual level. Secondly, we found this association was not robust to controlling for the age structure of a country. However, the analysis did not control for a number of other factors that may impact the relationship, such as seasonality, overall population health and lifestyle, or initial COVID-19 response time and strategy.

Other limitations are that there may be variation in COVID-19 death reporting methods and standards among countries and world regions leading to measurement error in the primary outcome. Similarly, measurement error may be present in the estimates of the prevalence of VDD among elderly due to variability in 250HD assays across studies (Table 1). Because data on vitamin D deficiency among older adults was collected from literature, there is selection bias in favor countries who conducted nutritional research on elderly populations in recent years. Specifically, countries in the Middle East, Africa and South America were underrepresented. We compared countries that were included in the study to those that were not $(n=114)$, we found that those in the study had significantly greater population size $(p=0.0005)$, share of the population over the age of $65(p<.0001)$ and total deaths at 50 days $(p<.0001)$. Additionally, in an analysis of death curves controlling for population size and age-structure, we found that early exponential growth of deaths was significantly slower in countries not included in the analysis compared to those that were.

\section{Conclusions}

Physiologic and social factors are likely each highly predictive of COVID-19 infection and mortality. Longer-term interventions upon the social issues that contribute to differential disease burden are necessary and justified for improvement of health equity beyond the COVID-19 pandemic. In the meantime, data indicate that correction of low vitamin D levels may be an important preventative 
intervention to address COVID-19 disparities. Furthermore, screening and treatment of VDI may constitute a future direction for additional prevention measures to reduce the burden of the COVID-19 pandemic among all populations.

\section{Abbreviations}

1. vitamin D deficiency (VDD)

2. vitamin D insufficiency (VDI)

3. Interleukin (IL)

\section{Declarations}

\section{Ethics approval and consent to participate:}

Not applicable

\section{Consent for publication:}

Not applicable

\section{Availability of data and materials:}

All data sourced for this analysis were taken from publicly-available databases and/or published scientific literature. The dataset supporting the conclusions of this article are included within the article and its additional files.

\section{Competing interests:}

Not applicable

\section{Funding:}

Not applicable

\section{Authors' Contributions:}

FL conceived the study. KB and DD completed data collection. DD performed statistical analyses. All authors contributed to results interpretations and manuscript writing. All authors read and approved the final manuscript

\section{Acknowledgements:}

Not applicable

\section{References}

1. Baggett TP, Keyes H, Sporn N, Gaeta JM. Prevalence of SARS-CoV-2 Infection in Residents of a Large Homeless Shelter in Boston. JAMA. 2020:5-6. doi:10.1001/jama.2020.6887

2. Oran DP, Topol EJ. Prevalence of Asymptomatic SARS-CoV-2 Infection A Narrative Review. Ann Intern Med. 2020;(6):M20-3012. doi:10.7326/M20-3012

3. Jolliffe DA, Griffiths CJ, Martineau AR. vitamin D in the prevention of acute respiratory infection: Systematic review of clinical studies. J Steroid Biochem Mol Biol. 2013;136:321-329. doi:10.1016/j.jsbmb.2012.11.017 
4. Marshall B, Bennett N, Smith A, Oh R, Burket J. Can vitamin D prevent acute respiratory infections: A systematic review and metaanalysis says yes, but the dosages used may not be what you'd expect. J Fam Pract. 2019;68(4):230-231.

5. Beard JA, Bearden A, Striker R. vitamin D and the anti-viral state. J Clin Virol. 2012;50(3):194-200. doi:10.1016/j.jcv.2010.12.006

6. Greiller CL, Martineau AR. Modulation of the Immune Response to Respiratory Viruses by vitamin D. Nutrients. 2015;7:4240-4270. doi:10.3390/nu7064240

7. Huang C, Wang Y, Li X, et al. Clinical features of patients infected with 2019 novel coronavirus in Wuhan, China. Lancet. 2020;395(10223):497-506. doi:10.1016/S0140-6736(20)30183-5

8. Gunville CF, Mourani PM, Ginde AA. The Role of vitamin D in Prevention and Treatment of Infection. Inflamm Allergy Drug Targets. 2013;12(4):239-245. doi:10.2174/18715281113129990046

9. Telcian AG, Zdrenghea MT, Edwards MR, et al. vitamin D increases the antiviral activity of bronchial epithelial cells in vitro. Antiviral Res. 2017;137:93-101. doi:10.1016/j.antiviral.2016.11.004

10. McCartney D, Byrne D. Optimisation of vitamin D Status for Enhanced Immuno-protection Against Covid-19. Ir Med J. 2020;113(4):58.

11. Holick MF, Binkley NC, Bischoff-Ferrari HA, et al. Evaluation, treatment, and prevention of vitamin D deficiency: An endocrine society clinical practice guideline. J Clin Endocrinol Metab. 2011;96(7):1911-1930. doi:10.1210/jc.2011-0385

12. Hossein-nezhad A, Holick MF. vitamin D for Health: A Global Perspective. Mayo Clin Proc. 2013;88(7):720-755. doi:10.1016/j.mayocp.2013.05.011

13. van Schoor NM, Lips P. Best Practice \& Research Clinical Endocrinology \& Metabolism Worldwide vitamin D status. Best Pract Res Clin Endocrinol Metab. 2011;25(4):671-680. doi:10.1016/j.beem.2011.06.007

14. Souberbielle J-C, Massart C, Brailly-Tabard S, Cavalier E, Chanson P. Prevalence and determinants of vitamin D deficiency in healthy French adults: the VARIETE study. Endocrine. 2016;53(2):543-550. doi:10.1007/s12020-016-0960-3

15. Cashman KD, Muldowney S, McNulty B, et al. vitamin D status of Irish adults: findings from the National Adult Nutrition Survey. Br J Nutr. 2013;109(7):1248-1256. doi:10.1017/S0007114512003212

16. Hagenau T, Vest R, Gissel T, et al. Global vitamin D levels in relation to age, gender, skin pigmentation and latitude: an ecologic meta-regression analysis.

17. Yu S, Fang H, Han J, et al. The High Prevalence of Hypovitaminosis D in China. Medicine (Baltimore). 2015;94(8):e858. doi:10.1097/MD.0000000000000585

18. Sayed-Hassan R, Abazid N, Alourfi Z. Relationship between 25-hydroxyvitamin D concentrations, serum calcium, and parathyroid hormone in apparently healthy Syrian people. Arch Osteoporos. 2014;9:176. doi:10.1007/s11657-014-0176-1

19. Parva NR, Tadepalli S, Singh P, et al. Prevalence of vitamin D Deficiency and Associated Risk Factors in the US Population (20112012). Cureus. 2018;10(6):e2741. doi:10.7759/cureus.2741

20. Forrest KYZ, Stuhldreher WL. Prevalence and correlates of vitamin D deficiency in US adults. Nutr Res. 2011;31(1):48-54. doi:10.1016/j.nutres.2010.12.001

21. Zheng Z, Peng F, Xu B, et al. Risk factors of critical \& mortal COVID-19 cases: A systematic literature review and meta-analysis. $J$ Infect. 2020;S0163-4453(20):30234-30236. doi:10.1016/j.jinf.2020.04.021

22. Ilie PC, Stefanescu S, Smith L. The role of vitamin D in the prevention of coronavirus disease 2019 infection and mortality. Aging Clin Exp Res. 2020;32(7):1195-1198. doi:10.1007/s40520-020-01570-8

23. Ali N. Role of vitamin D in preventing of COVID-19 infection, progression and severity. J Infect Public Health. 2020. doi:10.1016/j.jiph.2020.06.021

24. Daneshkhah A, Eshein A, Subramanian H, Roy HK, Backman V. The Role of vitamin D in Suppressing Cytokine Storm in COVID-19 Patients and Associated Mortality. medRxiv. May 2020:2020.04.08.20058578. doi:10.1101/2020.04.08.20058578

25. Pugach IZ, Pugach S. Strong Correlation Between Prevalence of Severe vitamin D Deficiency and Population Mortality Rate from COVID-19 in Europe. medRxiv. July 2020:2020.06.24.20138644. doi:10.1101/2020.06.24.20138644

26. COVID-19 Case Surveillance Public Use Data | Data | Centers for Disease Control and Prevention. https://data.cdc.gov/CaseSurveillance/COVID-19-Case-Surveillance-Public-Use-Data/vbim-akqf. Accessed August 25, 2020.

27. Gallagher JC. vitamin D and Aging. Endocrinol Metab Clin North Am. 2013;42(2):319-332. doi:10.1016/j.ecl.2013.02.004

Page $10 / 13$ 
28. Brouwer-Brolsma EM, Vaes AMM, van der Zwaluw NL, et al. Relative importance of summer sun exposure, vitamin D intake, and genes to vitamin D status in Dutch older adults: The B-PROOF study. J Steroid Biochem Mol Biol. 2016;164:168-176.

doi:10.1016/j.jsbmb.2015.08.008

29. van Orten-Luiten A, Janse A, Dhunukshe-Rutten R, Witkamp R. vitamin D deficiency as adverse drug reaction? A cross-sectional study in Dutch geriatric outpatients. Eur Jouran/ Clincial Pharmacol. 2016;72:605-614. doi:10.1007/s00228-016-2016-2

30. Huang $\mathrm{C}-\mathrm{H}$, Huang Y-TA, Lai Y-C, Sun C-K. Prevalence and predictors of hypovitaminosis D among the elderly in subtropical region. PLoS One. 2017;12(7):e0181063. doi:10.1371/journal.pone.0181063

31. Coronavirus Pandemic (COVID-19) - Statistics and Research - Our World in Data. https://ourworldindata.org/coronavirus. Accessed August 10, 2020.

32. Littell, R. C., Milliken, G. A., Stroup, W. W., Wolfınger, R. D., Schabenberger O. SAS for Mixed Models. 2nd Editio. Cary, North Carolina: SAS Institute; 2006.

33. Munshi R, Hussein MH, Toraih EA, et al. vitamin D insufficiency as a potential culprit in critical COVID-19 patients. J Med Virol. July 2020. doi:10.1002/jmv.26360

34. Meltzer DO, Best TJ, Zhang H, Vokes T, Arora V, Solway J. Association of vitamin D Deficiency and Treatment with COVID-19 Incidence. medRxiv Prepr Serv Heal Sci. 2020. doi:10.1101/2020.05.08.20095893

35. D'avolio A, Avataneo V, Manca A, et al. 25-hydroxyvitamin D concentrations are lower in patients with positive PCR for SARS-CoV2. Nutrients. 2020;12(5). doi:10.3390/nu12051359

36. Quesada-Gomez JM, Entrenas-Castillo M, Bouillond R. vitamin D receptor stimulation to reduce acute respiratory distress syndrome (ARDS) in patients with coronavirus SARS-CoV-2 infections. J Steroid Biochem Mol Biol. 2020;202:105719. doi:10.1016/j.jsbmb.2020.105719

37. Martineau AR, Jolliffe DA, Hooper RL, et al. vitamin D supplementation to prevent acute respiratory tract infections: systematic review and meta-analysis of individual participant data. BMJ. 2017;356:i6583. doi:10.1136/bmj.i6583

38. Goncalves-Mendes N, Talvas J, Duale C, et al. Impact of vitamin D Supplementation on Influenza Vaccine Response and Immune Functions in Deficient Elderly Persons: A Randomized Placebo-Controlled Trial. Front Immunol. 2019;10:65.

doi:10.3389/fimmu.2019.00065

39. Lau FH, Majumder R, Torabi R, et al. vitamin D Insufficiency is Prevalent in Severe COVID-19. medRxiv. 2020.

40. Grant WB, Lahore H, McDonnell SL, et al. Evidence that vitamin d supplementation could reduce risk of influenza and covid-19 infections and deaths. Nutrients. 2020;12(4). doi:10.3390/nu12040988

41. Pittaway J, Ahuja K, Beckett J, Bird M, Robertson I, Ball M. Make vitamin D while the sun shines, take supplements when it doesn't: a longitudinal, observational study of older adults in Tasmania, Australia. PLoS One. 2013;8(3):e59063. doi:10.1371/journal.pone.0059063

42. Mathei C, Van Pottelbergh G, Vaes B, Adriaensen W, Gruson D, Degryse J. No relation between vitamin D status and physical performance in the oldest old: results from the Belfrail study. Age Ageing. 2013;42(2):186-190. doi:10.1093/ageing/afs186

43. Lopes J, Fernandes G, Takayama L, Figueiredo C, Pereira R. A predictive model of vitamin D insufficiency in older community people: from the São Paulo Aging \& Health Study (SPAH). Maturitas. 2014;78(4):335-340. doi:10.1016/j.maturitas.2014.05.023

44. Ekwaru J, Ohinmaa A, Veugelers P. The effectiveness of a preventive health program and vitamin D status in improving healthrelated quality of life of older Canadians. Qual Life Res. 2016;25(3):661-668. doi:10.1007/s11136-015-1103-7

45. Sakem B, Nock C, Stango Z, et al. Serum concentrations of 25-hydroxyvitamin D and immunoglobulins in an older Swiss cohort: results of the Senior Labor Study. BMC Med. 2013;11:176. doi:10.1186/1741-7015-11-176

46. Chen J, Yun C, He Y, Piao J, Yang L, Yang X. vitamin D status among the elderly Chinese population: A cross-sectional analysis of the 2010-2013 China national nutrition and health survey (CNNHS). Nutr J. 2017;16(1). doi:10.1186/s12937-016-0224-3

47. Rothenbacher $D$, Klenk J, Denkinger M, et al. Prospective evaluation of renal function, serum vitamin $D$ level, and risk of fall and fracture in community-dwelling elderly subjects. Osteoporos Int. 2014;25(3):923-932. doi:10.1007/s00198-013-2565-5

48. Orces CH. vitamin D Status among Older Adults Residing in the Littoral and Andes Mountains in Ecuador. ScientificWorldJournal. 2015;2015:545297. doi:10.1155/2015/545297

49. Aly W, Hussein M, Moahamed Ebeid S, Mortagy A. Prevalence of vitamin D insufficiency among community dwelling elderly in Dakahlia as a representative of rural areas in Egypt. Aging Clin Res Exp Res. 2014;26(1):47-51. doi:10.1007/s40520-013-0139-1

Page $11 / 13$ 
50. Casey C, Woodside J V, McGinty A, et al. Factors associated with serum 25-hydroxyvitamin D concentrations in older people in Europe: the EUREYE study. Eur J Clin Nutr. 2019;73(2):319-328. doi:10.1038/s41430-018-0353-1

51. Aregbesola A, Voutilainen S, Nurmi T, Virtanen J, Ronkainen K, Tuomainen T. Serum 25-hydroxyvitamin D3 and the risk of pneumonia in an ageing general population. J Epidemiol Community Heal. 2013;67(6):533-536. doi:10.1136/jech-2012-202027

52. Aspell N, Laird E, Healy M, Shannon T, Lawlor B, O'Sullivan M. The Prevalence and Determinants of vitamin D Status in Community-Dwelling Older Adults: Results from the English Longitudinal Study of Ageing (ELSA). Nutrients. 2019;11(6):1253. doi:10.3390/nu11061253

53. Suryanarayana P, Arlappa N, Sai Santhosh V, et al. Prevalence of vitamin D deficiency and its associated factors among the urban elderly population in Hyderabad metropolitan city, South India. Ann Hum Biol. 2018;45(2):133-139. doi:10.1080/03014460.2018.1425479

54. Laird E, O'Halloran AM, Carey D, et al. he Prevalence of vitamin D Deficiency and the Determinants of 25(OH)D Concentration in Older Irish Adults: Data From The Irish Longitudinal Study on Ageing (TILDA). J Gerontol A Biol Sci Med Sci. 2018;73(4):519-525. doi:10.1093/gerona/glx168

55. De Vita F, Lauretani F, Bauer J, et al. Relationship between vitamin D and inflammatory markers in older individuals. Age (Dordr). 2014;36(4):9694. doi:10.1007/s11357-014-9694-4

56. Nakamura K, Kitamura K, Takachi R, et al. Impact of demographic, environmental, and lifestyle factors on vitamin D sufficiency in 9084 Japanese adults. Bone. 2015;74:10-17. doi:10.1016/j.bone.2014.12.064

57. Doo M. The association between sleep duration and 25-hydroxyvitamin $d$ concentration with obesity in an elderly korean population: A cross-sectional study. Nutrients. 2018;10(5). doi:10.3390/nu10050575

58. Rontoyanni V, Avila J, Kaul S, Wong R, Veeranki S. Association between Obesity and Serum 25(OH)D Concentrations in Older Mexican Adults. Nutrients. 2017;9(2):97. doi:10.3390/nu9020097

59. de Koning E, Verweij L, Lips P, Beekman A, Comijs H, van Schoor N. The relationship between serum 25(OH)D levels and anxiety symptoms in older persons: Results from the Longitudinal Aging Study Amsterdam. J Psychosom Res. 2017;97:90-95. doi:10.1016/j.jpsychores.2017.04.005

60. Santos A, Amaral TF, Guerra RS, et al. vitamin D status and associated factors among Portuguese older adults: results from the Nutrition UP 65 cross-sectional study. BMJ Open. 2017;7(6):e016123. doi:10.1136/bmjopen-2017-016123

61. Chirita-Emandi A, Socolov D, Haivas C, Calapis A, Gheorghiu C, Puiu M. vitamin D Status: A Different Story in the Very Young versus the Very Old Romanian Patients. PLoS One. 2015;10(5):e0128010. doi:10.1371/journal.pone.0128010

62. Safonova Y, Zotkin E, Glazunova G, Strukov E. Analysis of security by vitamin D of the elderly people. Adv Gerontol. 2018;31:184190.

63. Robien K, Butler LM, Wang R, et al. Genetic and environmental predictors of serum 25-hydroxyvitamin D concentrations among middle-aged and elderly Chinese in Singapore. Br J Nutr. 2013;109(3):493-502. doi:10.1017/S0007114512001675

64. Chuang SC, Chen HL, Tseng WT, et al. Circulating 25-hydroxyvitamin D and physical performance in older adults: A nationwide study in Taiwan. Am J Clin Nutr. 2016;104(5):1334-1344. doi:10.3945/ajcn.115.122804

65. Kositsawat J, Barry LC, Kuchel GA. C -Reactive Protein, vitamin D Deficiency, and Slow Gait Speed. 2013. 61(9):1574-1579. doi:10.1111/jgs.12403

66. Chutterpaul P, Paruk F, Cassim B. Prevalence of vitamin D deficiency in older South Africans with and without hip fractures and the effects of age, body weight, ethnicity and functional status. J Endocrinol Metab Diabetes South Africa. 2019;24(1):10-15. doi:10.1080/16089677.2018.1534360

\section{Figures}




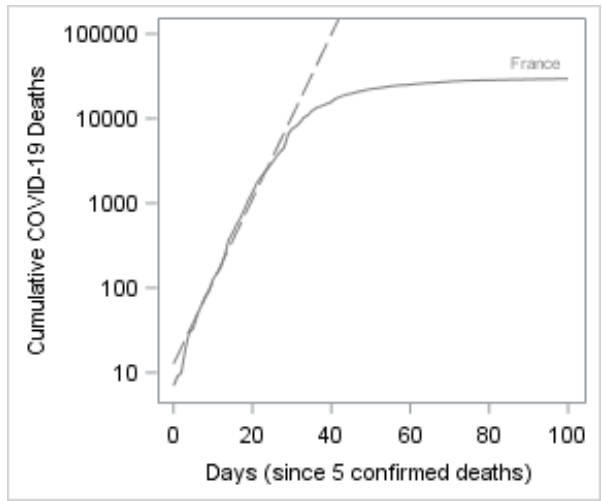

\section{Figure 1}

Cumulative deaths during the novel 2019 coronavirus outbreak in France Note: Modeling of the outbreak in France demonstrate early exponential growth.

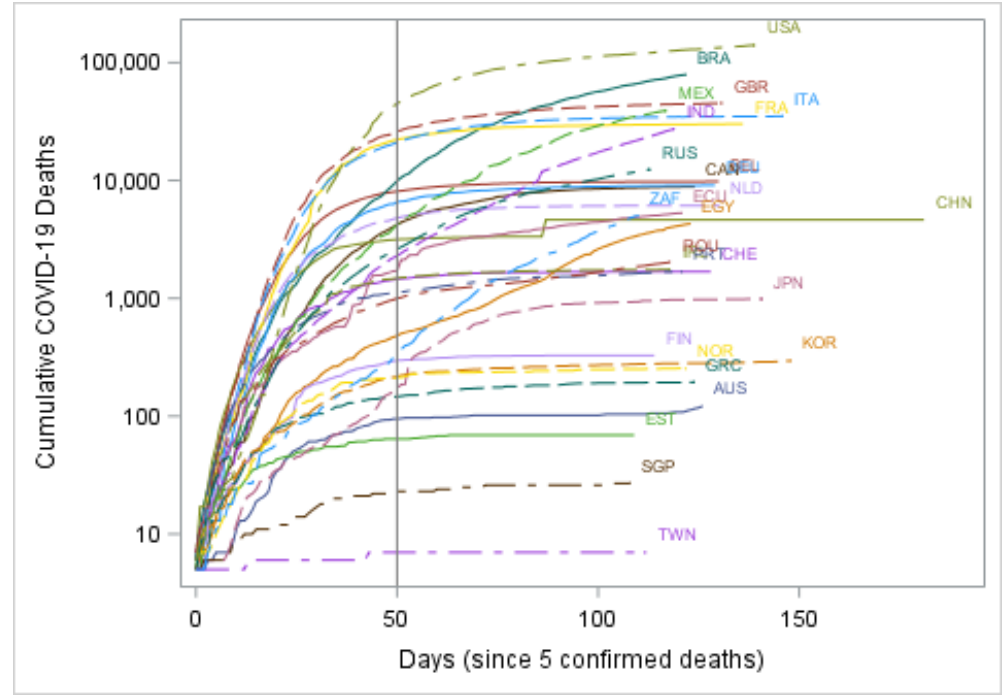

Figure 2

Cumulative deaths during 2019 coronavirus outbreak for the international sample of countries included in the analysis Note: $\mathrm{n}=29$ countries included in this analysis.

\section{Supplementary Files}

This is a list of supplementary files associated with this preprint. Click to download.

- PRISMA2009checklistVDD.doc

- SupplementaryInformation.docx 